\title{
A Workshop about the Future of Enterprise Information Systems
}

\author{
Per Svejvig ${ }^{1}$ and Charles Møller ${ }^{2}$ \\ ${ }^{1}$ Aarhus University, Business and Social Sciences, Department of Business Administration, \\ Haslegaardsvej 10, 8210 Aarhus V, Denmark \\ psveaasb. dk \\ ${ }^{2}$ Aalborg University, Department of Business and Management, \\ Center for Industrial Production, Fibigerstræde 10, 9220 Aalborg Ø, Denmark \\ charles@production.aau.dk
}

\begin{abstract}
Enterprise Information Systems (EIS) can be classified into three generations, starting with the application-centric, moving on to the data-centric and then to contemporary thinking, which can be described as process-centric. The overall theme of CONFENIS 2011 was to re-conceptualize EIS. One way of re-conceptualizing is to start with a blank sheet and "think out of the box". This topic was addressed in a workshop at CONFENIS 2011 which focused on the future of EIS. The workshop consisted of a large number of experts from across the world, divided into seven groups, who discussed the topic using LEGO SERIOUS PLAY to facilitate and stimulate the discussions. The group of seven came up with seven challenges for the future of EIS and we propose that the next generation of EIS should be conceptualized as human-centric.
\end{abstract}

Keywords: Future Workshop, Enterprise Information Systems, LEGO SERIOUS PLAY.

\section{Introduction}

The Fifth International Conference on Research and Practical Issues in Enterprise Information Systems (CONFENIS 2011) was held in October 2011 in Aalborg, Denmark. CONFENIS is now an established conference with representation from all over the globe. More than 80 experts from around the world were gathered together in Aalborg and to exchange knowledge and discuss EIS. This year's overall theme was Re-conceptualizing Enterprise Information Systems (EIS).

One way to re-conceptualize is to start with a blank sheet and "think out of the box", that is, to try to think differently or from a new perspective. The organizing committee for CONFENIS 2011 decided to hold a workshop about "the Future of EIS" to contribute to the overall theme of re-conceptualizing EIS. This workshop explored the combined knowledge of the participants about the challenges and potential features of future EIS, using the LEGO SERIOUS PLAY method [1].

The purpose of this chapter is to present the process and the results from the workshop. 
The LEGO SERIOUS PLAY method was used to facilitate and stimulate the discussions at the workshop [2]. The participants were divided into seven groups and each group was challenged to come up with their view on the future of EIS.

The seven groups each identified their number one challenge for the next five years: (1) Security, (2) Transparency of control, (3) User simplicity, (4) Rights management, (5) Standards, (6) IT and business working in a cooperative environment, and (7) Human business systems. The way these challenges were approached will be explained in this chapter with relation to the group work.

The chapter is organized in the following way. The next section presents the methodology, using LEGO SERIOUS PLAY to stimulate and facilitate the discussion. The seven major challenges are then reported on in the following section. This is followed by detailed presentations of five cases representing the results from five out of the seven groups. Finally we present our view of the next generation of EIS and the paper concludes with implications and suggestions for further research.

\section{Methodology}

\subsection{Brief about the Workshop Process}

The workshop took about two hours and consisted of several steps managed by a workshop facilitator. The seven groups were formed ad hoc. First, the facilitator introduced the workshop question "How can we conceptualize the Enterprise Information System of the future?" The facilitator explained that this is not an easy question with an easy answer and therefore there could be a lot of different answers based on different viewpoints. The viewpoints can be expressed metaphorically as different slices of a potato symbolizing the EIS, while the potato is a big and fluffy. The slices make up different images based on the workshop participants' theoretical and practical understanding of future EIS. Then he explained about how our hands and fingers can stimulate our cognitive thinking by building models and prototypes. This approach was taken further by playing (not to be confused with gaming) using LEGO SERIOUS PLAY (LSP) to facilitate and stimulate the play [see also 3, 4]. Working with complex problems and concepts in a playful way can produce a high degree of creativity.

Secondly, the facilitator moved the audience through different exercises in order for them to learn the language of LSP by building small LEGO models.

Thirdly, each workshop participant was asked to build the future EIS in 2016 (five years time from now) as an individual exercise. After the building process, each model was presented for the others in the group.

Fourthly, the final step was to build a shared model in the group by using the individual models, although adding parts to the model and removing redundant parts was still allowed. This shared model represented the team's final and conclusive work. At the end of the workshop, this model was formally presented to the other groups and the main future challenge was identified in each group. The groups were required to name unique challenges (There was no overlap between groups). 


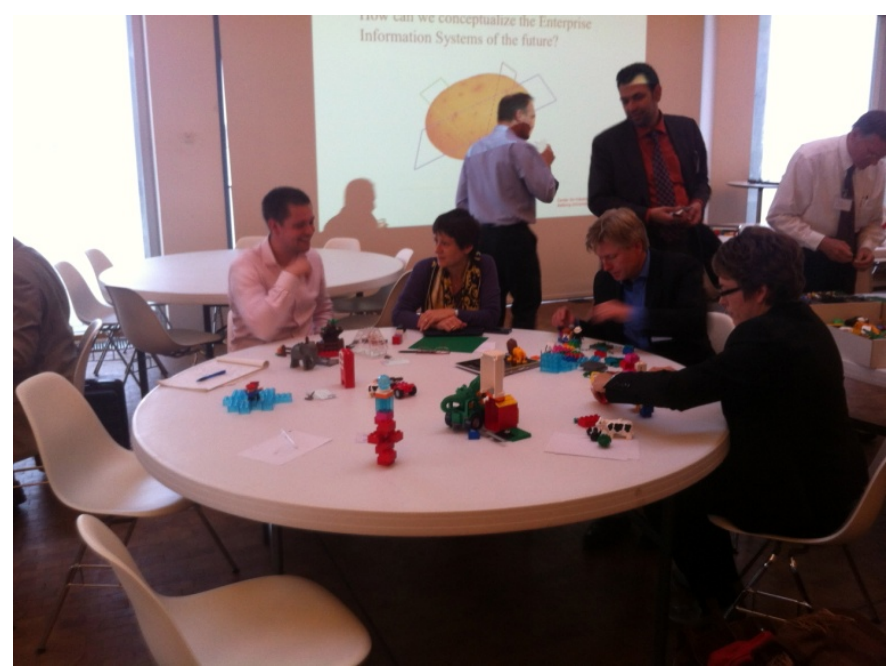

Fig. 1. LEGO SERIOUS PLAY workshop session

\subsection{Data Collection}

One of the authors of this paper had the role of carrying out participant observation [5] and of capturing the workshop by video recording [6]. Several student assistants supported the process by taking pictures from the workshop and video recording the final models prepared by the seven groups and providing formal feedback to the audience. This ensured that the activities that were simultaneously being carried out were sufficiently documented.

\subsection{Data Analysis}

The videos were transcribed and coded in NVivo [7]. The transcription process contained both visual elements (e.g. annotation of pictures) and verbal elements. Some of the videos were very difficult to transcribe, due to the noisy environment and the multifarious English accents. Pictures were selected to represent the shared models. Videos from the two groups were missing, so the detailed presentations of the group work covered five groups. Videos, pictures, transcriptions etc. were used to theorize about the major challenges with future EIS and to come up with proposals for the next generation of EIS.

\section{The 7 Major Challenges of Future EIS}

The shared conception of the next generation EIS is remarkably uniform. All groups began by assuming that three of the main challenges of EIS today already would have been solved in the future:

Firstly, EIS is considered to be ubiquitous. This on the agenda on this year's CONFENIS conference and we can see in people's minds that the idea of the EIS 
being available everywhere- easily accessible from the grid-is considered to be a certainty. It is interesting that also this is seen as a potential driver for more green and sustainable IT solutions in the future.

Secondly, EIS is considered to be extremely flexible. This is despite one of the prominent challenges of the existing EIS being that they are infamous for being inflexible and thus hindering the business innovation of enterprises locked into systems logic. The LEGO brick itself is considered the ultimate model for IT solutions or services, packed into units with well-defined interfaces making the future of EIS potentially extremely versatile.

Thirdly, EIS is considered to be relevant. There are many new technologies today and also new approaches that could leave the EIS as outdated legacy systems. Not surprisingly for EIS researchers, the EIS is viewed as being likely to be present in both the back-office and the front office in terms of playing a new role for business organizations.

This is also the starting point for the first challenge of the next generation of EIS, as characterized by seven inter-related challenges.

\subsection{IT and Business Working in a Cooperative Environment}

Today there is a lot of attention being given to the gap between IT and business organizations. In the future the participants in EIS, IT and business organizations will work together to solve business problem, with EIS as an underlying technology to support intelligent decision making and solutions.

\subsection{Human Business Systems}

Today we can define EIS as being mainly a technology for supporting management control systems. In the next generation of EIS, we will see much more emphasis on EIS as a foundation for human centered business systems. This implies the existence of access to EIS by means that are independent from time and space.

\subsection{User Simplicity}

EIS today is characterized by often being difficult to use by the ordinary and occasional business user. In the future EIS will have to simplify their user interfaces and the logic behind their functionality must be simplified where the user is involved. This challenge also includes including mobile access from gadgets such as iPads and other future smart devices.

\subsection{Transparency of Control}

The most important way that the next generation of EIS can be made simple is to make the controls transparent. Lack of visibility is one of the major drivers of complexity and creating transparency of control is one way of making it apparent to the users what is cause and what is effect in the business. 


\subsection{Rights Management}

In order to support the new networked business architecture, the future EIS must manage rights in a different way. When we are dealing with smart devices we cannot be sure that one person is in front of a computer or a person requiring information could be outside of the organization, e.g. they could be located at a supplier's. This creates a tremendous challenge regarding the management of rights.

\subsection{Security}

Various security issues that will have to be managed and solved in order to open up enterprise data to be accessed outside an enterprise. Today a new security update can be considered safe until the bad guys crack the code. Then a new security update is needed. This is not good enough in an enterprise setting. So new approaches to security will be required in the future EIS.

\subsection{Standards}

Finally, in order to advance the maturity of the EIS, overall standards are needed. These are needed, not only to sustain technological standards but also a process standards. These also point towards achieving flexibility and as such are a prerequisite for flexibility and versatility.

These seven interrelated and to some extent cascading challenges were considered to be the most important challenges by the participants in the workshop. These can be seen as the major findings from this study. Together they span an opportunity for space for future EIS research.

\section{Five LEGO Models Representing different Views on the Future of EIS}

This section reports on the immediate understanding and interpretation of future EIS in five out of the seven groups.

\subsection{Group 1}

Fig. 2, as shown below, captures the conceptualization of the future EIS by group 2 . The model is annotated with concepts explained by the group.

Today we completed our future version of an EIS system in five minutes [assembled however from the individually produced future EIS systems in the group]. Now I would like to present the [future EIS] system. The name of the system is Elephant. An elephant is a symbol of luck and longevity, so our system will survive from generation to generation. 
There are five major strengths of our system:

1) Our system is a bug free system. We can see that the bugs (pointing at the LEGO model) are kept out of the system by the fences and the hem. There is another hem if they break into the first fence, but they cannot get into the second one. We have very tight controls.

2) The second feature of our system is versatility. This is a very flexible system in a comprehensive / complicated world. There are many different kinds of features (again pointing to elements in the LEGO model) and it is effective to update and change them.

3) The third strength is in monitoring threats. We have a monitoring system with which they can watch the outside world and the system will be able to react to threats.

4) The fourth feature is that we will "break the old habits". If you think of existing EIS systems, they are like blocks or circles, but we have different shapes, we have blocks, we have circles, we have triangles, we have elephants - so we can break the old habits!

5) Finally the last one is maybe the most important. We can integrate a lot of subsystems so that the world can work happily together.

This is our version of our future EIS system (applause) - Thank you!

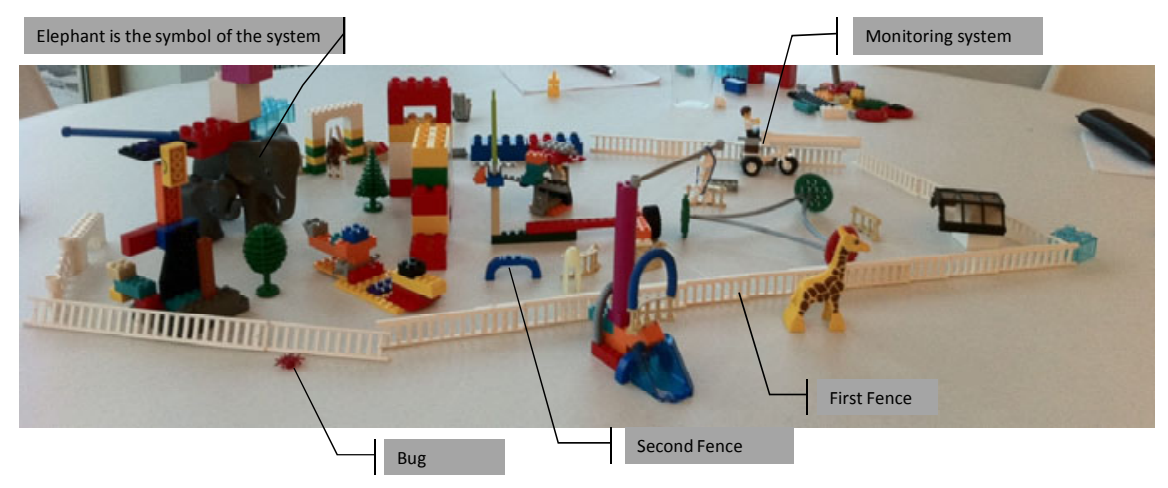

Fig. 2. LEGO Model from group 1

The group decided that security is the biggest challenge for future EIS, and this is clearly represented in their LEGO model.

\subsection{Group 2}

Group 2 came up with the following model in Fig. 3 describing the future EIS. The group describes the model as follows:

What we have here is our conceptualization of the EIS...this is characterized by: 
1) Transparency

2) Process factory ability

3) Pervasive computing anywhere and any time

4) Directions to be able to drive our processes and the processes [delivered by] a process provider. There is a process to drive an organization towards the goal in an efficient way. Adjusting the processes day by day and ensuring that the goals of the organizations can be driven in the right direction

5) Flexible sensors to sense what is happening in the outside environment and then to deal with pressure from competitors, the market, and from regulators

6) We also have some interaction with mobile devices, so we are very flexible and can see them as a mechanism or as a bridge to an external provider

We furthermore have controller busses (in the middle of the picture) [to take care of controlling processes]. We have this management information both for the inside and also for the outside, to retain a high degree of transparency. The system also has the horizontal support of processes for manufacturing, sales, finance, and other uses. The system will be very powerful in the future.

Group 2 selects transparency of control as the main challenge illustrated by the inside / outside management information system.

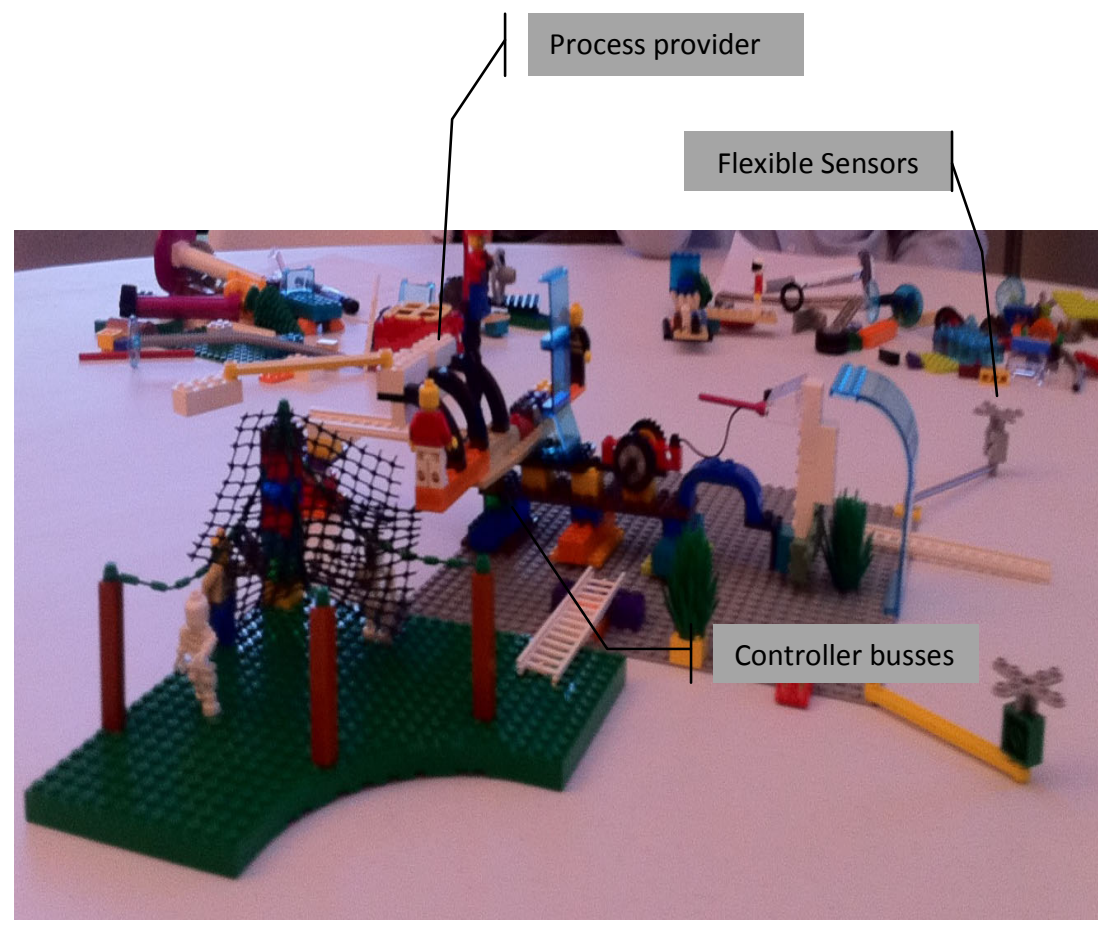

Fig. 3. LEGO model from group 2 


\subsection{Group 3}

Fig. 4 below shows how group 3 conceptualizes the future of EIS:

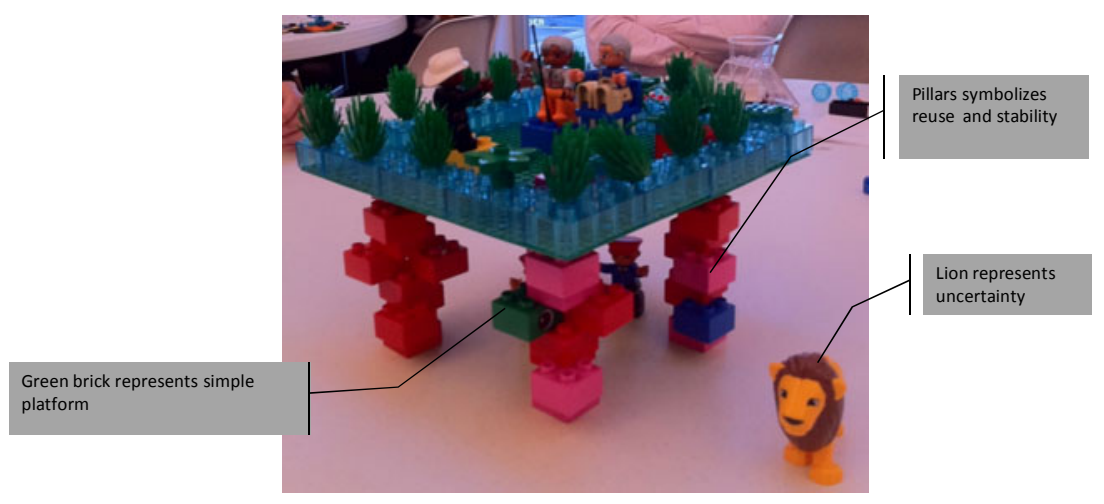

Fig. 4. LEGO Model from group 3

The group explains the future EIS artifact in this way:

First of all, everything is built around the user: 'humans first' is the motto and it is all placed in a green environment. So we look into the future and in five years' time it is important to consider the green elements within it. Then what we will have is the interconnectivity of the different elements, built on a very simple platform. That green one is the simple platform, but everything is built on stable and flexible pillars using the LEGO building blocks. They are not stuck together in a rigorous or inflexible way, but rather in a flexible way... That is the reason why we say that our artifact is reusable and stable.

The element of the uncertainty [expressed by the lion]... Yes you need to speak about the uncertain. You never know what will happen - security management is also important.

The biggest challenge, according to this group, is user simplicity.

\subsection{Group 4}

The conceptualization from group 4 is shown in Fig. 5:

The group presents their model as follows: This is a very ecological energy facility where we have all hardware in the computer department and the security and then it is connected to the rest of the world.

The connection is with the user and the eco system. The ecosystem is the green lawn where users have cover and it is ready to be used as the user wishes.

There are different things (pointing at the model) that can support the user when they connect to something.

And then we have two animals representing all obstacles and new challenges. The elephant is here but it might be attacked by the lion. 


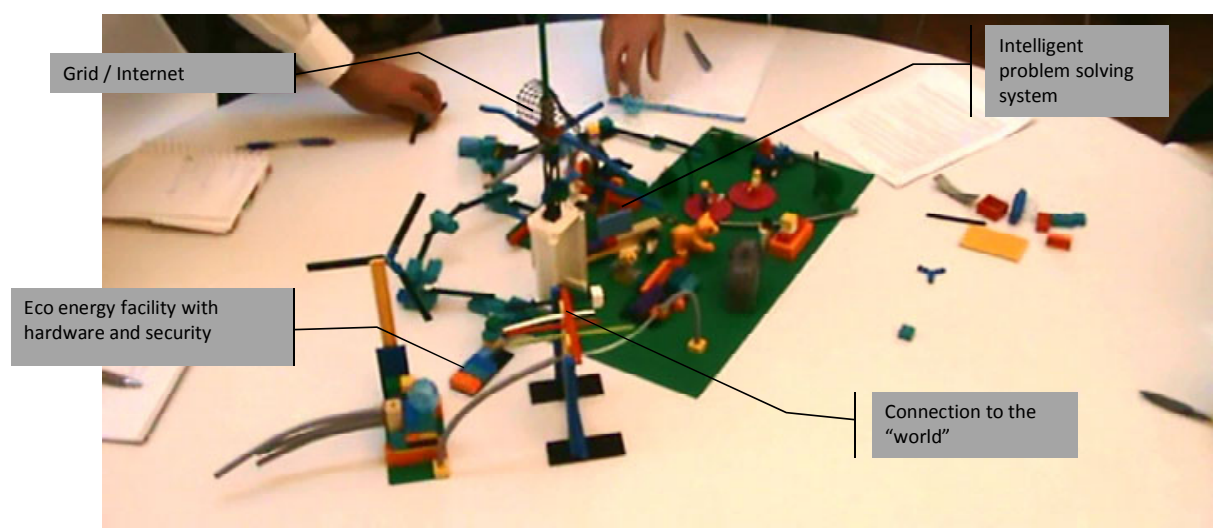

Fig. 5. LEGO Model from group 4

Here is the problem solver with an intelligent problem solving system that is also responsible for solving... new challenges which may arise when using this very flexible model and a sense of the environment, in combining different parts that interconnects together for intelligent problem solving.

Also, in this environment, small pieces of standardized applications can connect to the infrastructure and speak the same language, so as to connect.

All the legacy stuff is hidden in the basement where no one can touch it. Here are two users [Pink platform]. Both are localized and they can work from home. They can recognize their system as being very intuitive, but [they] are also able to travel around the universe using different gadgets to access the data that is hidden somewhere here (pointing...) This is so that security issues can be solved locally and that the users will have access to their data.

And what did I forget?... Oh yes this is the grid Internet that is actually all over everywhere and this represents the stability that is very standardized, and to which you easily can connect and disconnect.

The biggest challenge for group 4 was rights management which is related to security well expressed in the model.

\subsection{Group 5}

Group 5 conceptualizes the future EIS as shown in Fig. 6:

The group describes their model as follows: First of all, things must be interconnected. We can make a clear distinction between the two elements [LEGO plates] the system itself with its base [green LEGO plate], the various elements and what the system does [grey LEGO plate] in terms of extending the capability of human beings...alone and in connection with others, so we see the system as being in the sky or the clouds. 


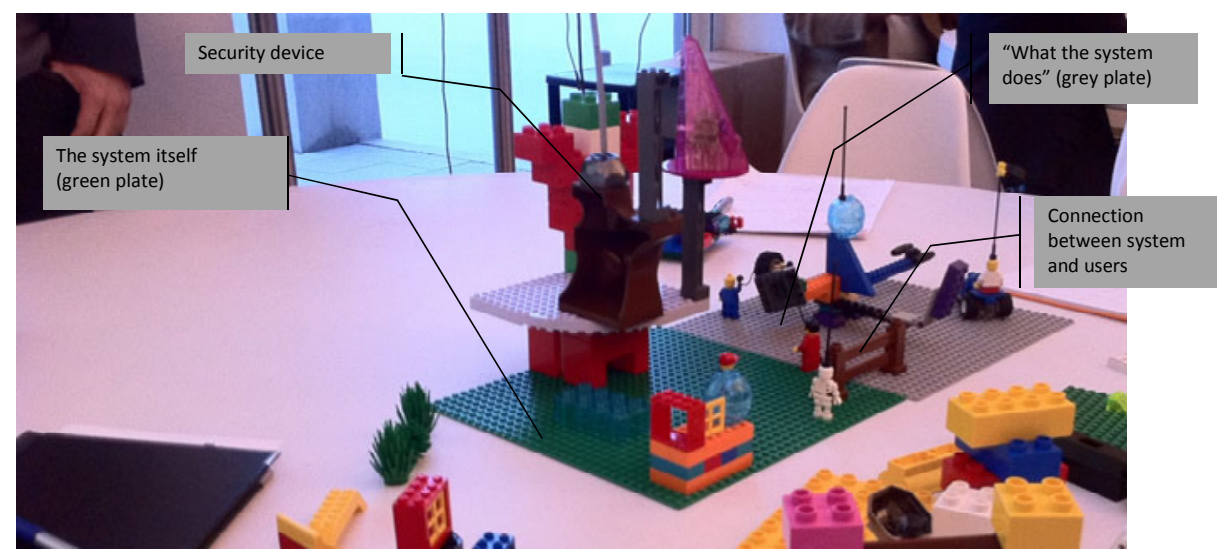

Fig. 6. LEGO model from group 5

We have five challenges:

1. One is people versus technology so we can make it adaptable so that people actually want to use it.

2. Then we have standards, they have flexibility and we can make them applicable to our needs in terms of their use.

3. We have security. It is pretty obvious that vital information should not be revealed (brown knight].

4. A means of safe storing of data ensuring security and privacy, so data is not lost.

5. A mechanism to capture user requirements in a rapid way without it taking five years to develop. That is a real challenge.

Group 5 emphasizes standards as their key challenge.

\section{$5 \quad$ Next Generation Enterprise Information System}

We have now presented the findings from the CONFENIS workshop on the future of EIS. The workshop methodology has been presented, as have the conceptual models made by the groups. The challenges of future EIS have been presented as an aggregate conceptual model of future EIS. EIS have evolved through different generations and the challenges presented here could point towards the next generation of EIS.

It is possible to classify the three first generations of EIS in this way:

- First generation EIS can be considered to be application-centric in the sense that the applications contain the data, and the business rules are not necessarily integrated.

- Second generation EIS can be considered to be data-centric and driven by the integrated databases enabled by the DBMS technology. 
- Third generation EIS can be considered to be process-centric and driven by the BPM architecture, supported by the integrated systems.

What characterizes the next generation EIS is of cause yet to be seen, but we can speculate on the challenges based on the three previous generations of EIS.

Table 1. Four generations of EIS

\begin{tabular}{|l|l|l|l|l|}
\hline EIS generation & $\begin{array}{l}\text { Application- } \\
\text { centric }\end{array}$ & $\begin{array}{l}\text { Data- } \\
\text { centric }\end{array}$ & $\begin{array}{l}\text { Process- } \\
\text { centric }\end{array}$ & $\begin{array}{l}\text { Human- } \\
\text { centric }\end{array}$ \\
\hline & MRP & ERP & BPM & $?$ \\
\hline $\begin{array}{l}\text { Business } \\
\text { Challenge }\end{array}$ & Efficacy & Efficiency & Effectiveness & Resilience \\
\hline $\begin{array}{l}\text { Organizational } \\
\text { challenge }\end{array}$ & $\begin{array}{l}\text { Support of } \\
\text { departments }\end{array}$ & $\begin{array}{l}\text { Support of } \\
\text { enterprises }\end{array}$ & $\begin{array}{l}\text { Support of } \\
\text { supply chains }\end{array}$ & $\begin{array}{l}\text { Support of } \\
\text { business } \\
\text { networks }\end{array}$ \\
\hline $\begin{array}{l}\text { Technology } \\
\text { Enablers }\end{array}$ & Databases & $\begin{array}{l}\text { DBMS, } \\
\text { Client-server } \\
\text { architecture }\end{array}$ & Internet, SOA & $\begin{array}{l}\text { Semantic } \\
\text { networks, } \\
\text { Social } \\
\text { Media, } \\
\text { Cloud } \\
\text { computing }\end{array}$ \\
\hline Integrates... & Applications & Data & Processes & Humans \\
\hline Timeline & Around 80'ies & $\begin{array}{l}\text { Around } \\
\text { 90'ies }\end{array}$ & Around 00'ies & $\begin{array}{l}\text { Around } \\
10 \text { 'ies }\end{array}$ \\
\hline
\end{tabular}

The evolution of the EIS has been driven by the business challenges and by the resulting organizational challenges. In the discussions in the groups the volatile nature of today's business environment was taken as a premise. Following this premise the organization of enterprises does not follows the hierarchical logic of the past, but is characterized by being network oriented and spanning across organizational boundaries. But mainly the evolution has been driven by the enabling technologies. The role of technology in EIS is an interesting topic to pursue. E.g. this year there was a track at the conference focusing on the impact of cloud computing on EIS. EIS technologies are of cause influenced by the general trends in information technology but in order to become game changers in EIS other factors are required.

Based on the experience of the workshop we can conclude that the next generation EIS will be human-centric. Human-centric EIS are characterized by being: 1) ubiquitous; 2) flexible; and 3) relevant to the business. The seven challenges that were the main findings support the thinking of human-centric and cascading challenges: 1) Standards; 2) Security; 3) Transparency of control; 4) User simplicity; 5) Rights management; 6) IT and business working in a cooperative environment; and 7) Human business systems. 


\section{Conclusion}

This chapter has pursued to illustrate a possible future of EIS. This was addressed in a workshop at CONFENIS 2011 consisting of a large number of experts from across the world, divided into seven groups, who discussed the topic using LEGO SERIOUS PLAY to facilitate and stimulate the discussions. The group of seven came up with seven challenges for the future of EIS, which were overall conceptualized as the human-centric EIS.

There are conceptual and methodological implications from this study. First, if we consider other ways of modeling the future through scenario building approaches like the "Shell Energy Scenario 2050" [8] or "Supply Chain 2020" [9], the participants generally share a fairly optimistic view of the future business environment and a positive view of the role of technology in the future. This is perhaps not surprising since most of the researchers are working with various technologies. However this attitude could also have been produced by "group effects" in an atmosphere of enthusiasm for EIS where participants might have a tendency to express accepted views [10]. The workshop should therefore be seen as a creative and thoughtful inspiration for a continued discussion about the future EIS. Further studies involving the EIS community (vendors, consultants, users, researchers etc.) might bring this discussion to a much more refined level.

Second, the research methods used for the workshop are interesting topics itself. The methods combine LEGO SERIOUS PLAY for visualization and cognitive thinking [4] with video documentation [6, 11]. However we encountered several practical and methodological issues (e.g. noisy environment and lack of structured documentation from groups), which has hampered this study. We do nevertheless see the approach as promising for future research and practice as a tool to multimodal imagery which brings together verbal/narrative, visual/imagistic, and kinesthetic/ haptic modes [3] documented by video.

Despite the implications and limitations, this study has anyway provided some evidence of trends that may help researchers in selecting topics in the future and for practitioners to make sense of the next generation of EIS.

\section{References}

1. Hansen, P., Fradinho, M., Andersen, B., Lefrere, P.: Changing the way we learn: towards agile learning and co-operation (2009)

2. Mabogunje, A., Kyvsgaard Hansen, P., Eris, O., Leifer, L.: Conference SWINGSimulation, Workshops, Interactive eNvironments and Gaming: An Integrated Approach to Improve Learning, Design, and Strategic Decision Making, pp. 277-286 (Year)

3. Bürgi, P., Roos, J.: Images of Strategy. European Management Journal 21, 69-78 (2003)

4. Gauntlett, D., Holzwarth, P.: Creative and visual methods for exploring identities. Visual Studies 21, 82-91 (2006)

5. Myers, M.D.: Qualitative Research in Business \& Management. Sage Publications, London (2009) 
6. Pink, S.: Doing Visual Ethnography. Images, Media and Representation in Research. Sage Publications, London (2007)

7. Bazeley, P.: Qualitative Data Analysis with NVivo. Sage Publications Ltd., London (2007)

8. Shell International BV: Shell Energy Scenarios to 2050. Shell International BV (2008)

9. CLT Supply Chain 2020: SC2020 Baseline Scenarios. MIT Center For Transportation and Logistics (2009)

10. Bryman, A.: Social Research Methods. Oxford University Press, Oxford (2008)

11. Pink, S.: Walking with video. Visual Studies 22, 240-252 (2007) 